\title{
MEASURING PRICE ELASTICITIES FOR RESIDENTIAL WATER DEMAND WITH LIMITED INFORMATION
}

\author{
H. Allen Klaiber \\ V. Kerry Smith \\ Michael Kaminsky \\ Aaron Strong \\ Working Paper 18293 \\ http://www.nber.org/papers/w18293 \\ NATIONAL BUREAU OF ECONOMIC RESEARCH \\ 1050 Massachusetts Avenue \\ Cambridge, MA 02138 \\ August 2012
}

Partial support for this research was provided by the Decision Center for a Desert City. Special thanks are due two referees for exceptionally careful and constructive comments on an earlier draft of this paper. We are responsible for any remaining errors. The views expressed herein are those of the authors and do not necessarily reflect the views of the National Bureau of Economic Research.

NBER working papers are circulated for discussion and comment purposes. They have not been peerreviewed or been subject to the review by the NBER Board of Directors that accompanies official NBER publications.

(C) 2012 by H. Allen Klaiber, V. Kerry Smith, Michael Kaminsky, and Aaron Strong. All rights reserved. Short sections of text, not to exceed two paragraphs, may be quoted without explicit permission provided that full credit, including $\odot$ notice, is given to the source. 
Measuring Price Elasticities for Residential Water Demand with Limited Information H. Allen Klaiber, V. Kerry Smith, Michael Kaminsky, and Aaron Strong NBER Working Paper No. 18293

August 2012

JEL No. H42,Q25

\section{$\underline{\text { ABSTRACT }}$}

This paper exploits the seasonal and annual changes in marginal prices for water to estimate the price elasticity of demand by residential households for water. It uses the changes in distributions of water using the census block group levels in response to changes in marginal prices of water for matched months across years. This strategy reduces the interaction effects of outdoor use and demographic fact in determining responsiveness to price. By comparing years that vary in overall water availability the framework can recover measures of how responses to price vary with season and draught conditions. The application is the urban Phoenix metropolitan area.

\author{
H. Allen Klaiber \\ The Ohio State University \\ Department of Agricultural, Environmental \\ and Development Economics \\ 332 Ag Admin Building \\ 2120 Fyffe Rd \\ Columbus, $\mathrm{OH} 43210$ \\ klaiber.16@osu.edu \\ V. Kerry Smith \\ Department of Economics \\ W.P. Carey School of Business \\ P.O. Box 879801 \\ Arizona State University \\ Tempe, AZ 85287-9801 \\ and NBER \\ kerry.smith@asu.edu
}

\author{
Michael Kaminsky \\ $\$$ QDO VV** URXS \\ 111 Huntington Ave \\ Boston, MA 02199-7636 \\ michael.kaminsky@asu.edu
Aaron Strong
School of Urban and Regional Planning
The University of Iowa
347 Jessup Hall
Iowa City, IA 52242
aaron-strong@uiowa.edu


Measuring Price Elasticities for Residential Water Demand with Limited Information

\section{Introduction}

There is a growing recognition in both the professional and popular literatures that water scarcity is a key policy issue which is essential to address in evaluating the effects of climate change and long term sustainability of economic growth. ${ }^{1}$ Glennon’s [2009] observations in his book, Unquenchable: America’s Water Crisis and What to Do About It, describe the problem well:

“Water presents a surprising riddle. We can neither make nor destroy it, so our supply is fixed yet it's exhaustible because, as a shared resource used repeatedly, some uses preclude future reuse. Water policy suffers from a profound discontinuity between science and law...the result epitomizes the tragedy of the commons: limitless access to a finite resource” (p. 324)

Those evaluating the water problem usually conclude prices must be reformed so that incentives facing water users reflect this scarcity. Demand functions provide the basic economic relationships required to predict how water use will respond to such changes. This is where the problems arise. Access to detailed information on household water use including household attributes (i.e. lot size, landscaping composition, and presence of swimming pools), the composition of use (i.e. indoor versus outdoor usage), and pricing is limited. The combination of concerns over confidentiality and in some

\footnotetext{
${ }^{1}$ See Covich [2009] for a detailed assessment of the climate change and water challenges.
} 
cases legislation precluding access to micro-level data for individual customers served by water providers creates a limited information setting for understanding water demand. Nonetheless, following Chetty's [2009] arguments, it is possible under some conditions to recover key structural water demand parameters without either a structural model or the ability to use data on specific customers.

In our application, the demand parameter we estimate is the price slope of a water demand function for residential consumers at different water consumption levels. We use this parameter to construct estimates for the price elasticity of demand, a key policy variable of interest to local water providers. Our analysis uses order statistics derived from micro level information on residential metered water use and prices which protects the confidentiality of individual water customers. We control for unobservables by exploiting our ability to link consumption and price data to spatial units. An important element in our strategy stems from the ability to observe price and water consumption changes over time.

In most water demand applications increasing block rate structures confound a reduced form approach for recovering information about a structural parameter such as the quantity response to a price change. Our application has only two blocks. Nearly all residential consumers are in the second block and do not switch blocks when water prices change. In many areas of the country where there is metering and pricing of water more complex increasing block pricing structures are often found. Pricing policies with multiple blocks transform the methods required to use records on households' water consumption patterns for estimating how the quantity of water used responds to price 
changes. ${ }^{2}$ They also make the requirements for detailed information on household attributes even more important. As a result of the increased modeling requirements associated with more complex pricing structures it has been difficult to offer a detailed characterization of the differences in water demand responses across small versus large residential users. This shortcoming has direct policy relevance because there is broad consensus in the U.S. that affordable access to water for "ordinary" household use must be maintained for lower income groups.

This paper proposes a simple method for estimating the price elasticity of demand that meets policy needs and can accommodate current data limitations. It can also be implemented in the presence of simple increasing block pricing structures, such as the two block structure used in Phoenix, AZ. In short, our method can estimate how water usage responds to price changes under the typical conditions confronting applied researchers with limited access to detailed household level micro data. Our data sample was constructed as the thresholds for percentiles of water consumption at the census block group level for a single municipal provider in Phoenix, AZ. Using the changes in water consumption for selected percentiles over time our approach controls for housing attributes, landscape attributes that don't change, and socio-economic characteristics of consumers while maintaining confidentiality of individual households' records.

The seasonal and temporal changes in the Phoenix municipal water system's residential water rates are used to reconstruct a record of price changes that are exogenously imposed on customers. The Phoenix water provider is a regulated utility which is allowed to adjust prices annually to cover cost increases. By matching months

\footnotetext{
${ }^{2}$ See Olmstead et al. [2007] for a derivation of the relationship between conditional and unconditional price elasticities.
} 
that experienced changes in the marginal price for the same pricing block it is possible to isolate the quantity adjustment associated with these specific price changes and be assured there is no shifting of households between price blocks. ${ }^{3}$ The findings derived using this simple strategy are striking. Despite limited price variation we estimate statistically significant demand elasticities. Our results also allow the price responsiveness to be distinguished by percentiles of consumption. Distinguishing the price responsiveness of demand by the amount of water consumption we are able to establish that there are relatively large differences in elasticities with the largest water users appearing to be more price inelastic.

Estimation involves matching years where we compare two normal precipitation years as well as a normal precipitation year to an exceptionally dry year. Separate models are estimated for winter and summer demand. A comparison of the estimates for approximately comparable price changes when there are different patterns of natural precipitation conditions provides a simple plausibility check for the logic of the model. That is, we should expect that natural increases in the need for water (due to dry conditions) would make households with significant outside uses of water less responsive to price increases. This is exactly what we find. The estimates of price elasticities for residential customers in the summer months across all consumption percentiles reveal they are much less responsive to price changes when the price comparison involves responses in water use during dry conditions.

\footnotetext{
${ }^{3}$ This strategy is consistent with Chetty's [2009] call for a middle ground between structural and reduced form (or treatment effect) approaches to policy evaluation. He describes how research in public economics has focused on what he labels a "sufficient statistic" or estimation strategies that focus on measuring parameters in transparent ways with credible identifying information and yet focus on the key economic parameter for policy evaluation and often welfare statements.
} 
The remainder of the paper is structured as follows. Section two outlines our model and discusses its relationship to the conditional demand approach widely advocated for estimating price elasticities with increasing block prices as well as to a recent contribution by Nataraj and Hanemann [2011] exploiting a drought related water pricing change in Santa Cruz. ${ }^{4}$ The third section describes our data and empirical estimates. We conclude with comments on the applicability of our new approach in other situations where response of water usage to price changes must be evaluated with limited information.

\section{Modeling Water Demand}

\section{A. Background}

Most of the recent literature measuring the price elasticity of demand has been based on the discrete / continuous choice (DCC) model developed by Hausman [1979] for applications to labor supply. ${ }^{5}$ For demand models derived from choices with convex budget sets (increasing block price structures), one need only specify a conditional demand function to estimate the model. This relationship describes how the quantity demanded responds to the marginal price within each budget segment (corresponding to the segment associated with each step in the increasing block pricing structure). Conventional practice assumes this demand function includes two errors. One is usually

\footnotetext{
${ }^{4}$ An alternative structure based on using the first order conditions from the constrained utility maximization problem is developed and illustrated in Strong and Smith [2010]. ${ }^{5}$ See Burtless and Hausman [1978] for discussion of the model with non-convex budget constraint, Heckman [1983] for a critique and Reiss and White [2006] for discussion of how welfare analysis can be undertaken with non-linear budget constraints.
} 
hypothesized to be associated with household preference heterogeneity not captured in observable variables. This feature is known to the household but not to the analyst. The second is an error hypothesized to be unknown to both the household and the analyst. It could arise from leaks in the water system, measurement errors, or a composite of both effects. The two error terms allow the model to describe choice outcomes. This structure is especially important for being able to include some households' consumption choices that would appear to have them falling at the kinks of the budget constraint.

As a rule, the consumption decision process is explained as if there were two distinct steps: (1) a description of the probability that consumption will be in one of the budget segments (or at a kink) ${ }^{6}$ and (2) conditional on each budget segment there is a conditional demand function describing how the quantity of water demanded relates to the marginal price. ${ }^{7}$ At a kink, there is no such relationship because the model implies demand is higher than the highest value of the lower block but lower than the lowest value of the next highest block. The parameters of the conditional demand are assumed constant across segments to identify the model. ${ }^{8}$ This assumed constant parameter structure for all budget segments does not simplify the relationship between conditional and unconditional price elasticities.

As Olmstead et al. [2007] demonstrate, the unconditional price elasticity is a function of both the conditional price elasticity and the income elasticity. As a result, the

\footnotetext{
6 There will be multiple kinks for more complex increasing block structures with several steps in the increasing block structure.

${ }^{7}$ In practice we simply observe households consumption that implies their consumption affects the marginal price they face. The steps are used to separate the way the statistical model uses available information so that the inherent simultaneity is represented consistently in the econometric analysis.

${ }^{8}$ See Strong and Smith [2010] for a discussion of the limitations of this assumption.
} 
relationship of the unconditional price elasticity to the conditional elasticity is not clear. Both the ranking of the two measures and the magnitude of the absolute difference between them cannot be signed a priori. For their application Olmstead et al. found the unconditional price elasticity of demand was smaller in absolute magnitude than the conditional elasticity. Because the rate subsidies associated with increasing block price structures are small, the price differences between blocks are small, and the expenditure share for water in a household's overall budget is small; the authors suggest their results may provide a reasonable guide for the relationship with most communities' residential water demands.

Nonetheless, despite this relatively optimistic conclusion of the Olmstead et al. study, the experience with the DCC model for water applications has been mixed. Hewitt and Hanemann [1995] reported the first such application. They found large (in absolute value) conditional price elasticities and report an unconditional elasticity for a price structure change that is also large compared to the literature. Both the Espey et al. [1997] and the Dalhausen et al. [2003] meta analyses of water demand studies found the majority of the price elasticity estimates were less than unity in absolute magnitude. Olmstead et al.’s results are consistent with these findings in that their conditional elasticity estimate was approximately -0.34 and simulated unconditional estimates was 0.59 .

The Olmstead et al. sample is also quite unique in that it pools household level data across 11 urban areas in the U.S. ${ }^{9}$ One concern the authors raise is that the very advantage of their data in displaying how households responded to a variety of price

\footnotetext{
${ }^{9}$ The data are relatively old as are the data underlying Hewitt and Hanemann [1995].
} 
structures may create a cause for concern. That is, the community's tastes for water conservation may be reflected in the provider's rate structure. Communities with several blocks and high marginal prices for the top blocks may also have strong mandates for conservation. This logic seems especially relevant for public water providers where revenues cannot exceed costs. Under these conditions revenues in excess of the costs of service for the highest blocks must be offset by revenues below the costs of service for lower blocks in order to meet the zero "profit" constraint.

In these situations the estimation of demand functions that are structured to be conditional to a rate structure may also reflect the unobserved taste for conservation. After a series of tests for this potential explanation of their findings Olmstead et al. conclude that they cannot dismiss the hypothesis that the underlying city level taste for conservation, through the design selected for each community’s price structure, may contribute to the observed higher (in absolute value) elasticities. It would not be possible to reproduce their study using a single water provider because the structure of a single system's price schedule is usually stable. Year to year changes in prices may well involve small changes in marginal prices for selected blocks that are unlikely to have sufficient variability in prices to distinguish the effect of a change in price from changes in conservation motives over time. ${ }^{10}$

Recently Nataraj and Hanemann [2011] have exploited a natural demand shock for water pricing in Santa Cruz, California using a regression discontinuity design to

\footnotetext{
${ }^{10}$ One exception to this is Pint [1999] who estimates the DCC model for the Alameda County Water District but argues that it would be difficult to take the results from the estimation to other parts of California since the results are sensitive to climatic conditions, a key point of our analysis. Additionally, the information available for her analysis includes detailed information on household characteristics including house size and lot size.
} 
estimate how households responded to a new block in the block pricing schedule. In response to a prolonged period of drought and after using price increases and various non-price controls from 1987 to 1992, in February 1995 the Santa Cruz local government introduced new rates to begin in June 1995. Prior to this time there was a two block system. The 1994 rates priced the first eight hundred cubic feet (CCF) on the bi-monthly metering schedule at $\$ 0.65 / \mathrm{CCF}$ and the next units of water were priced at $\$ 1.55 / \mathrm{CCF}{ }^{11}$ The new third rate applied to consumption over 40 CCF and was initially priced at \$3.14/CCF for use in excess of 40 CCF in a two month period.

This pricing scheme implied households consuming 40 or more CCF would experience a change in the marginal price of consumption over this threshold. To exploit this change they use prior water consumption as the threshold distinguishing treatment and control households and investigate the effects of excluding households close to the 40 CCF cut off. Their findings indicate households did respond to the price change. This result was confirmed in both robustness checks for the threshold and falsification tests for the basic logic underlying the design. Unfortunately, the discrete nature of the price change and the fact that it was limited to the largest consumers made it difficult to develop general conclusions on the extent of price responsiveness to compare to the literature. The authors did note that the water consumption response estimated for the 100 percent price increase implied a short run price elasticity of approximately -0.12 . This estimate falls at the low end of past estimates.

Our method builds on the Nataraj and Hanemann [2011] logic and exploits a set of changes in the rate structure for residential customers in Phoenix, AZ that take place

\footnotetext{
${ }^{11}$ Increases in rates of 6\% in June 1995 and 5\% in June 1996 and 1997 were part of the plan to increase rates. The $5 \%$ rate increases in 1996 were to apply to the new block.
} 
with every change of season. These rate changes are common across many water providers in the Southwestern U.S. and are intended to reflect seasonal changes in demand and supply of water. We adapt a proposal made by Borenstein [2009] for considering residential elasticity demand and are able to consider how these changes affect consumers with different total amounts of water usage at different times of the year. Our approach does not estimate a structural demand. Instead, we hypothesize a price response that can be locally approximated for small price changes with a linear form. Changes in the distributions of water use in local neighborhoods, defined by census block groups, associated with price increases over time are used to estimate elasticities for different consumption percentiles. More specifically, we use the order statistics for these consumption distributions to characterize the responses for different sized water consumers to price changes.

\section{B. A Quasi-Experimental Approach for Measuring Price Elasticities for Residential $\underline{\text { Water Demand }}$}

Our analysis considers a single municipal water provider with a two block pricing structure. ${ }^{12}$ Rates change in different months throughout the year corresponding to low, medium, and high usage periods. Water and waste water are priced on the same metered records. Thus, changes in either price affect incentives for water usage. The consumption threshold for the increase in marginal price between blocks changes from 600 cubic feet in low water use periods (winter) to 1000 cubic feet in high water use periods (summer). Our estimation strategy exploits increases in rates over time that vary by different

12 The use of a block pricing structure is common for water providers; while the number of blocks and cutoff points between blocks varies widely across different providers. 
amounts for each usage period along with the ability to link individual meters to census block groups, with each block group containing approximately 600 residential water meters. To consider the first component of our analysis, the changes in marginal prices, we use a linear specification for water demand as in equation (1).

$w_{i j t}=\alpha_{0}+\alpha_{1} p_{j t b}+f\left(z_{i}\right)+g\left(T_{j t}\right)+u_{i j t}$

$w_{i j t}$ is the water consumed by household $i$ in the month $j$ of year $t$. Based on the metered records for $w_{i j t}$, we know $p_{j t b}$, which is the $b^{\text {th }}$ block's marginal price in month $j$ of year $t$. This is the block that corresponds to the water consumption $w_{i j t} \cdot f\left(z_{i}\right)$ is a function for the effects of observable household attributes $\left(z_{i}\right)$ and $g\left(T_{j t}\right)$ is the effect of weather related variables - temperatures and precipitation in month $j$ and year $t . u_{i j t}$ is an error that can be a composite of unobserved individual heterogeneity and measurement error.

To form a difference equation, we match the monthly records for each household (meter) in each year of our data. ${ }^{13}$ For customers who remain in a constant price block across years and months, we can difference equation (1) between two years in which a marginal price change occurs to derive equation (2).

$$
w_{i j t+a}-w_{i j t}=\alpha_{1} \bullet k+\left(g\left(T_{j t+a}\right)-g\left(T_{j t}\right)\right)+\left(u_{i j t+a}-u_{i j t}\right)
$$

\footnotetext{
${ }^{13}$ The Phoenix water provider changes rates every year to cover increased water delivery costs and maintenance.
} 
$k$ is the constant increment to the marginal price experienced between years (i.e. $t+a$ and $t$ ). Using this specification the intercept in this difference equation estimates the effect of price on water demand assuming the price change between the two months is identical for each consumer. These differences can be pooled over months if the price increment is the same. The differencing causes the demographic features, $z_{i}$ 's, characterizing individual households to drop from the estimating model. This outcome assumes these attributes don't change at the scale of the census block group. One might argue the lowest block's price should also be included in the vector of $z_{i}$ 's due to an adjustment in virtual income associated with the change in expenditures on the first block of water. If the lower block's price changes with linearity assumed for the effect of income on water demand and all households remain in the top consumption block we would expect the changes in this price to appear thru the income term. However, the quantity limits distinguishing the blocks do not change for a given season so this adjustment to income would be the same for all households. They would imply an adjustment to the intercept for our difference model. In our case over the years considered the first block’s price does not change.

Differencing eliminates the effects of the first block's price if the sample's consumption remains in the second block and the first block price doesn't change. Fortunately, as we explain below, there are no households with changes between the two blocks in response to the price changes for our sample. We did observe over the full year that there are some households who change consumption blocks at the lowest levels of water consumption in May. Considering the consumption levels realized by the top 80 to 85\% of the households in Phoenix and removing May from our sample we avoid the 
problems that would arise with households changing consumption blocks as prices change.

Equation (2) is best considered an approximation. It relies on the effect of price on water demand being locally constant. We would expect that price response would depend on the features of each residential consumer's living situation such as outdoor landscape, number of bathrooms, the composition of water using appliances, and so forth. We attempt to take account of these effects to estimate the changes in water demand at different levels of consumption. More specifically, we alter equation (2) and construct differences in the thresholds defining the $10,25,50,75$, and 95 percentiles for water consumption in each block group to arrive at our estimating equation given in (3).

$w_{n j t+a}-w_{n j t}=\alpha_{1} \bullet k+\left(g\left(T_{j t+a}\right)-g\left(T_{j t}\right)\right)+\left(\eta_{n j t+a}-\eta_{n j t}\right)$

Consumption percentiles are represented by the subscript $n$, and the precise thresholds could be different households in different years. As noted earlier, we assume the differences in the demographic attributes of households at each threshold defining the percentiles are small and can be neglected. This is a limitation that arises with our data. We do not have distributions for the economic and demographic attributes of households in the census block groups over time. This formulation follows Borenstein's [2009] proposal for the case of modeling electricity demand. When the assumption that the household defining each threshold has approximately the same attributes differencing the same percentile across time for each block group removes these effects. It also removes cross sectional features of neighborhoods that are constant across time, such as xeric or 
mesic landscape, that might interact with the consumption responses to marginal price changes.

As noted earlier only households at the lowest level of consumption display sufficient reactions in their water use to the price changes over time to observe a shift from one price block to another. Moreover, for this percentile, the changes that lead to shifts across pricing blocks are limited to one month, May. This month precedes the high use and highest price season. All of the remaining points on the distribution fall in the highest block. By focusing on the highest and lowest water usage periods of the year corresponding to winter and summer months, which do not include May, we avoid the issue of block switching. Our estimates discussed in the next section report all percentiles. Nonetheless for the lowest consumption groups demand responses may well, over the full year, reflect the influence of the price threshold between blocks. For this reason we argue the estimated water consumption response to prices is appropriate for residential consumers that account for all but the lowest 10 to 15 percent of water consumption.

Our strategy does allow us to estimate different conditional price elasticities for different sized residential users. To our knowledge, this issue has not been considered in the past literature. Nataraj and Hanemann [2011] measure the local price responsiveness for one class of demanders. We can extend that logic to consider nearly the full distribution of residential consumers. Moreover, it appears these types of distinctions can be important for pricing policy when there are concerns with assuring affordable access to low income users who tend to be in the lowest use percentiles. 


\section{Data and Price Elasticity Estimates}

Our analysis is based on records for residential meters served by the municipal Phoenix water system. We know the year, month, amount of water used, and the price schedule for each meter which we treat as a user. These data do not include other information about these households. ${ }^{14}$ After matching each meter to its block group and information on weather conditions experienced in each block group for each month and year we are left with between 993 and 996 records for each month in the three years comprising our sample. ${ }^{15}$

Our analysis relies on isolating changes in the marginal prices for water over time. These changes are not associated with any household moving between pricing blocks. Table 1 displays the marginal prices for the highest water usage blocks by month for the three years in our sample. This table depicts the changes in marginal prices that occur for the highest block in different seasons. There are some months that display differences from the low (December, January, February, March), medium (April, May, October, November), and high (June, July, August, September) periods due to the timing of allowed adjustments in the rate structure.

We use these monthly differences in prices for the low and the high usage period as exogenous price differences to construct the quasi-experiment. As noted this difference in the quantity thresholds for each consumption percentile at the block group level

\footnotetext{
14 This same limitation faced Nataraj and Hanemann. They used the average values for demographic variables for each block group. The structure of the price changes applied to every residential customer. As a result it is possible to difference out the effects of demographics and focus on the price and weather related differences in demand for the full distribution of consumers.

${ }^{15}$ Block groups are constant across years. The slight difference in numbers of block groups is a result of missing data.
} 
differences out the effects of the housing distribution and neighborhood attributes. During this period, the bulk of the new housing construction in the Phoenix area occurred outside the Phoenix water provider's district, making the assumption of constant housing and neighborhood attributes reasonable given the short time periods we consider.

As Table 1 suggests, we selected three years for analysis and treat the year 2000 as our base year. This strategy provides two different sets of price changes to evaluate using differences between the years 2000 versus 2002 and 2000 versus 2003. The years 2000 and 2003 were considered a pair of "normal" years in terms of precipitation while year 2002 was unusually dry. We use the effects of these weather differences on our elasticity estimates to judge the plausibility of our strategy for estimating price responsiveness. Table 2 compares the weather variables and percentiles of consumption use for each of the three years.

Our models also include controls for monthly differences in the minimum temperature, the precipitation, and the days of precipitation interpolated for each block group. These data came from approximately 15 NOAA monitoring stations located around the Phoenix area that collected information during the months used for our analysis. Each monitoring station reports daily data on temperatures and precipitation. We averaged temperatures in each month at each monitor to form a series of monthly specific temperature variables. For precipitation, we used monthly counts of the total number of days in which rainfall was detected as well as the total amount of rainfall (measured in inches). Each block group in our sample is assigned the weather data from the closest monitor. 
Different months experience different price changes. Comparing the price changes over all months between the years 2000 and 2003 we observe price changes varying from $\$ 0.14$ to $\$ 0.31$ (per 100 cubic feet). Eight months fall between the ranges of $\$ 0.14$ to $\$ 0.17$. Comparing years 2000 and 2002 the range is $\$ 0.08$ to $\$ 0.19$. The model is estimated separately for each of two sub-samples and each percentile - restricting the data to include only winter (low-December, January, and February) and only summer (high-June, July, August, and September) seasons.

Before discussing our estimates for price responsiveness we should discuss the implications of using a difference in an order statistic as the dependent variable in each model. We examine the quantity response to price changes at the $k$ percentile of consumption. There is a well-established literature on the properties of order statistics used in multivariate statistical models. Linear functions of order statistics are often known as L statistics and as L estimators when they are used to estimate parameters of an underlying distribution. When the $\mathrm{L}$ statistic is a function of a finite number of central order statistics or a finite number of extreme order statistics, we can use established properties of their asymptotic joint distribution to obtain the limiting distribution for the L statistics. For example, in the case of a fixed number of central order statistics the limiting distribution is normal under mild conditions on the parent distribution. Indeed, asymptotic normality has been established by putting relatively mild conditions on the weighting function or the parent distribution. ${ }^{16}$ Both are consistent with what would be conventional practice with analyses of micro data. Thus, it seems reasonable to interpret

\footnotetext{
${ }^{16}$ A good overview of these conditions with citations to the primary results is found in Chapter 8 of Arnold, Balakrishnan and Nagaraja [2008].
} 
the test statistics for our parameter estimates as asymptotically normal and follow conventional practices in interpreting the test statistics.

Table 3 reports our estimates for the first difference model for these two seasons and for each paired price change (2000-2003 and 2000-2002). The intercept in each set of models is the key focus of the analysis for evaluating the effects of price on consumption. This parameter is precisely estimated in comparing summer consumption for normal weather years. For winter use, large users are not responsive to price but otherwise respond during summer months. What is especially striking is the contrast when we consider a price change comparing a normal and a dry year. Here all users are price responsive but the pattern of adjustment is informative. In the summer months all users, but especially large users, are less responsive to price changes during dry conditions.

In comparing a dry and normal year changes in precipitation are the same sign in both winter and summer months. The amount of precipitation, as Table 2 shows, has declined so the change is negative between 2002 and 2000. This precipitation effect increases demand in both winter and summer. By contrast, in comparing the two normal years the effect depends upon season. To assess the overall impact we need to consider changes in the amount of precipitation and its distribution over days. Changes in each of these variables have opposite signs for the summer and winter models.

For the comparison of the normal and dry year the two effects are consistent between the winter and summer models. Reductions in precipitation lead to increases in water use and reductions in the number of days of precipitation reduce water usage for 
both seasons. Precipitation declines in the winter increase water use, while in the summer the effect depends on both the change in amount and days of precipitation. ${ }^{17}$

Table 4 presents the primary results of our analysis - estimates of the demand elasticity using comparisons between two normal years and a normal and a dry year to identify the price effect. Our estimates using percentiles can be distinguished by the size of residential customers. This distinction, as expected based on Nataraj and Hanemann [2011], plays an important role in parsing out the heterogeneity in household level estimates for the price elasticities.

Comparing the first panel of Table 4 for normal / normal versus the second panel for normal / dry we see directly that price responsiveness is reduced quite substantially for the summer months when the overall situation is abnormally dry. In winter months, we see responsiveness to price changes across all consumption percentiles. We also find that larger users are uniformly less responsive to price across all seasons regardless of weather conditions. To our knowledge this is the first time a water demand study has been able to extract these distinctions and control for the effects of the block structure.

\section{Implications}

When the DCC approach was first proposed to model labor supply and evaluate the effect of policies to change income taxes Heckman [1983] raised a number of questions about the ability of analysts to assume the actual points specifying the kinks in the budget constraint, due to tax structure, were exogenous. In addition, he noted that

\footnotetext{
${ }^{17}$ All the significance tests for the effects of individual variables use Huber robust standard errors.
} 
with exogenous kink points there should be "bunching at the kinks."18 These kink points are exogenous in the case of increasing block price structures for water; however in preliminary analysis of the Phoenix residential water data we did not observe this bunching. This may reflect the simplified rate structure residents in the Phoenix area faced where most residential customers are in the highest block throughout the year due to the relatively low consumption threshold defining pricing blocks. As a result, there would be no meaningful variation in the marginal price for these customers. The seasonal changes in rates would be experienced by all water consumers at the same time and responses to the price changes would be difficult to separate from changes in water needs due to the temperature changes throughout the year. The Phoenix system's price structure is not unique. As a result, it may be reasonable to assume the opportunities for adjustments among blocks for many water systems are limited and the distinction between conditional and unconditional price responses small. The “action” in estimating price responses may well be in considering price changes over time and allowing flexibility in the nature of the price response by the quantity of water consumed.

A further limitation to what has become the conventional approach to demand modeling, as Olmstead et al. suggest, is the concern about whether the price structure is truly exogenous. Under these conditions pooling data across communities to provide variation in price schedules may also include differences inherent in the conservation motives of the households in these communities. These types of applications also would not have sufficient information to distinguish taste parameters for conservation from the parameters reflecting price responses. Limiting the analysis to a single community would

${ }^{18}$ See Heckman [1983] p. 71. 
not provide a sufficient basis for identifying the price response either. This concern would lead to preferences for models that do not start with the conditional demand function defined for a given price structure and instead a framework that begins from a preference specification such as Strong and Smith [2010]. Of course, this approach adds considerable structure in the assumed specification for preferences.

We have proposed a different strategy for estimating demand responses more consistent with the compromise advocated by Chetty [2009]. It combines two elements. The first is Borenstein's proposal to consider how order statistics summarizing the distribution of use, constructed at the census block group level, change with exogenous price changes. The second element involves exploiting changes in marginal prices over time (to reflect provider cost increases) that can be matched by month so the position of water consumption in the price structure is unchanged. This matching process assures the increment to the marginal price can be used as an exogenous change from the household's perspective. As a result, the price change can be treated as a type of treatment for evaluating the change in water usage.

Our application to the Phoenix residential market indicates this approach is remarkably effective. It does not require the structural assumptions of the DCC approach, allows estimates of price responsiveness by size (in terms of water use) of customer, and was also effective in discriminating how lower than normal precipitation in an arid desert environment can reduce price responsiveness, especially for large users. We interpret this ability to detect a role for differences in seasonal rainfall as confirming evidence that supports our direct approach. It also indicates that matching a simple theoretical model of demand response with an exogenous source of price variation can allow measurement of 
demand elasticities. Our use of the order statistic to characterize demand provides a strategy that recognizes the importance of a price change to any individual household will depend on the amount of water used. More complex increasing block price schedules can be accommodated in this logic with enough ability to observe within block changes in marginal prices over time.

For empirical demand estimation, our findings of substantial heterogeneity and variation over time should be informative for the specification of future structural models. In addition to informing future structural models, there are also several limitations of the method provided in this paper that could be confronted in future research. Perhaps most glaring is that we rely on the relatively short time frame of study and relatively non-binding pricing block structure of Phoenix. Confronting endogeneity from changes in price blocks, how to handle differences across larger geographic areas such as metropolitan areas, and incorporation of longer-run changes in response through changes in appliances or landscape remain open questions deserving of future research. By demonstrating the ability to overcome the typical setting of limited access to micro data on water consumption information we hope that this approach offers a practical basis for meeting many of the needs of policy makers managing local water resources. Reliable estimates of price elasticities distinguished by seasonal and weather conditions can help to assess how water use (and provider revenues) will change with price changes. 


\section{References}

Arnold, Barry C., N. Balabrishnan and H.N. Nagaraja, 2008, A First Course in Order Statistics, (Philadelphia: SIAM).

Borenstein, Severin, 2009, “To What Electricity Price Do Consumers Respond? Residential Demand Elasticity Under Increasing Block Pricing,” presented to NBER summer workshop, Environmental and Energy Economics, July. Burtless, Gary and Jerry A. Hausman, 1978, “The effect of Taxation on Labor Supply: Evaluating the Gary Negative Income Tax Experiment,” Journal of Political Economy, 86(6):1103-1130.

Chetty, Raj, 2009, "Sufficient Statistics for Welfare Analyses: A Bridge Between Structural and Reduced-Form Methods," Annual Review of Economics, Vol. 1, pp. 451-488.

Covich, Alan P., 2009, Emerging Climate Change Impacts on Freshwater Resources, Resources for the Future Report, June.

Dalhuisen, Jasper M., Raymond J.G. M. Florax, Henri L.F. de Groot, and Peter Nijkamp, 2003, "Price and Income Elasticities of Residential Water Demand: A Meta Analysis,” Land Economics, Vol. 79 (May):292-308.

Espey, Molly, J. Espey, and W. Douglass Shaw, 1997, “Price Elasticity of Residential Demand for Water: A Meta Analysis,”Water Resources Research, Vol. 33 (April):1369-1374.

Glennon, Robert, 2009, Unquenchable: America's Water Crisis and What to Do About It, (Washington, D.C.: Island Press). 
Hausman, Jerry A., 1979, "The Econometrics of Labor Supply on Convex Budget Sets,” Economics Letters, Vol. 3: 171-174.

Hausman, Jerry A., 1983, "Stochastic Problems in the Simulation of Labor Supply,” in M. Feldstein, editor, Behavioral Simulations in Tax Policy Analysis (Chicago: University of Chicago Press), p. 41-69.

Heckman, James, 1983, “Comment” in M. Feldstein, editor, Behavioral Simulations in Tax Policy Analysis (Chicago: University of Chicago Press), p. 70-82.

Hewitt, Julie and Michael Hanemann,1995, “A Discrete-Continuous Choice Approach to Residential Water Demand under Block Rate Pricing,” Land Economics, 71(2): 173-192.

Kenney, Douglas S., Christopher Goemans, Robert Klein, Jessica Lowry and Kevin Reid, 2008, "Residential Water Demand Management: Lessons from Aurora Colorado,” Journal of the American Water Resources Association, Vol. 44 (February): 192207.

Nataraj, Shanthi and W. Michael Hanemann, 2011, “Does Marginal Price Matter? A Regression Discontinuity Approach to Estimating Water Demand,” Journal of Environmental Economics and Management, 61(2): 198-212.

Olmsted, Sheila M., W. Michael Hanemann and Robert N. Stavins,2007, "Water Demand Under Alternative Price Structures,” Journal of Environmental Economics and Management, 54(2): 181-198.

Pint, Ellen,1999, “Households Responses to Increased Water Rates During the California Drought," Land Economics, 75(2): 246-266. 
Reiss, Peter C. and Matthew W. White, 2006, “Evaluating Welfare with Nonlinear Prices,” NBER Working Paper No. 12370, July.

Saez, Emmanuel, 2002, “Do Taxpayers Bunch at Kink Points?” working paper, Department of Economics, University of California, Berkeley, June.

Strong Aaron and V. Kerry Smith, 2010, "Reconsidering the Economics of Demand Analysis with Kinked Budget Constraints,” Land Economics, 86(1): 173-190. 
Table 1: Monthly Variation in Marginal Prices for the Highest Water Blocks

\begin{tabular}{|c|c|c|c|c|c|c|c|c|c|c|c|c|}
\hline \multirow[b]{4}{*}{ Month } & \multicolumn{12}{|c|}{ Year } \\
\hline & \multicolumn{4}{|c|}{2000} & \multicolumn{4}{|c|}{2002} & \multicolumn{4}{|c|}{2003} \\
\hline & \multicolumn{12}{|c|}{ Marginal Prices for Highest Water Block } \\
\hline & 1.09 & 1.12 & 1.32 & 1.68 & 1.17 & 1.24 & 1.47 & 1.87 & 1.24 & 1.26 & 1.49 & 1.89 \\
\hline $\begin{array}{l}\text { January } \\
\end{array}$ & $\mathrm{X}$ & & & & $\mathrm{X}$ & & & & $\mathrm{X}$ & & & \\
\hline February & $\mathrm{X}$ & & & & $\mathrm{X}$ & & & & $\mathrm{X}$ & & & \\
\hline March & $\mathrm{X}$ & & & & & $\mathrm{X}$ & & & & $\mathrm{X}$ & & \\
\hline April & & & $\mathrm{X}$ & & & & $\mathrm{X}$ & & & & $\mathrm{X}$ & \\
\hline May & & & $\mathrm{X}$ & & & & $\mathrm{X}$ & & & & $\mathrm{X}$ & \\
\hline June & & & & $\mathrm{X}$ & & & & $\mathrm{X}$ & & & & $\mathrm{X}$ \\
\hline July & & & & $\mathrm{X}$ & & & & $\mathrm{X}$ & & & & $\mathrm{X}$ \\
\hline August & & & & $\mathrm{X}$ & & & & $\mathrm{X}$ & & & & $\mathrm{X}$ \\
\hline September & & & & $X$ & & & & $X$ & & & & $\mathrm{X}$ \\
\hline October & & & $X$ & & & & $X$ & & & & $X$ & \\
\hline November & & & $\mathrm{X}$ & & & & $\mathrm{X}$ & & & & $X$ & \\
\hline December & & $X$ & & & & $X$ & & & & $X$ & & \\
\hline
\end{tabular}


Table 2: Comparison of Weather Conditions and Water Usage in Normal Versus Dry Years

\begin{tabular}{|c|c|c|c|c|c|c|c|c|c|c|c|}
\hline \multirow[b]{3}{*}{ Water Usage Percentile } & \multicolumn{11}{|c|}{ Year / Classification } \\
\hline & \multicolumn{4}{|c|}{2000 / Normal } & \multicolumn{3}{|c|}{2002 / Dry } & \multicolumn{4}{|c|}{2003 / Normal } \\
\hline & & $m$ & $\sigma$ & & & $m$ & $\sigma$ & & $m$ & $\sigma$ & \\
\hline $10 \%$ & & 6.37 & 3.56 & & & 6.22 & 3.36 & & 5.76 & 3.42 & \\
\hline $25 \%$ & & 10.25 & 4.94 & & & 10.06 & 4.64 & & 9.40 & 4.68 & \\
\hline $50 \%$ & & 16.11 & 7.33 & & & 15.89 & 7.09 & & 15.02 & 7.28 & \\
\hline $75 \%$ & & 23.99 & 11.02 & & & 23.89 & 11.06 & & 22.62 & 11.33 & \\
\hline $90 \%$ & & 33.66 & 16.21 & & & 33.62 & 16.32 & & 31.99 & 16.69 & \\
\hline Weather ${ }^{\mathrm{b}}$ & $m$ & Min & & Max & $m$ & Min & $\operatorname{Max}$ & $m$ & Min & & Max \\
\hline Precipitation & 0.65 & 0 & & 4.86 & 0.3 & 0 & 1.78 & 0.75 & 0.1 & & 5.07 \\
\hline Precipitation Days & 2.5 & 0 & & 11.00 & 1.78 & 0 & 6.00 & 2.78 & 0.0 & & 9.00 \\
\hline
\end{tabular}

${ }^{a} \mathrm{~m}$ is the sample mean and $\sigma$ the standard deviation. Water is measured in units of 100 cubic feet

${ }^{b}$ Precipitation is in inches and precipitation days are a count of days with measurable precipitation 
Table 3: Water Consumption Difference Models: Normal Years and Normal / Dry Year ${ }^{\mathrm{a}}$

\begin{tabular}{|c|c|c|c|c|c|c|}
\hline \multirow[b]{2}{*}{ Percentile } & \multirow[b]{2}{*}{ Season } & \multicolumn{4}{|c|}{ 2003-2000 (Normal / Normal ) } & \multirow[b]{2}{*}{$\bar{N}$} \\
\hline & & Intercept $\Delta$ & Min Temp & $\Delta$ Precip & $\Delta$ Precip Days & \\
\hline \multirow{4}{*}{$10 \%$} & Summer & -0.83 & 0.14 & 0.34 & -0.14 & 3982 \\
\hline & & $-(15.22)$ & (5.95) & (4.61) & $-(5.54)$ & \\
\hline & Winter & -0.98 & 0.03 & -0.04 & 0.03 & 1992 \\
\hline & & $-(9.93)$ & (2.39) & $-(0.85)$ & $(0.85)$ & \\
\hline \multirow{4}{*}{$25 \%$} & Summer & -1.18 & 0.21 & 0.48 & -0.20 & 3982 \\
\hline & & $-(20.34)$ & $(8.42)$ & (5.74) & $-(7.03)$ & \\
\hline & Winter & -1.40 & 0.07 & 0.06 & -0.03 & 1992 \\
\hline & & $-(12.95)$ & (4.57) & $(0.97)$ & $-(0.83)$ & \\
\hline \multirow{4}{*}{$50 \%$} & Summer & -1.52 & 0.31 & 0.69 & -0.27 & 3982 \\
\hline & & $-(22.25)$ & (9.98) & (6.78) & $-(8.24)$ & \\
\hline & Winter & -1.94 & 0.09 & 0.20 & -0.11 & 1992 \\
\hline & & $-(14.11)$ & $(4.51)$ & (1.75) & $-(1.70)$ & \\
\hline \multirow{4}{*}{$75 \%$} & Summer & -1.89 & 0.45 & 1.25 & -0.38 & 3982 \\
\hline & & $-(19.42)$ & $(10.30)$ & (8.51) & $-(8.43)$ & \\
\hline & Winter & -2.98 & 0.15 & 0.30 & -0.13 & 1992 \\
\hline & & $-(15.06)$ & (5.07) & (2.62) & $-(1.80)$ & \\
\hline \multirow{4}{*}{$90 \%$} & Summer & -2.16 & 0.52 & 1.64 & -0.41 & 3982 \\
\hline & & $-(14.94)$ & $(8.02)$ & (7.93) & $-(6.25)$ & \\
\hline & Winter & -4.04 & 0.19 & 0.49 & -0.22 & 1992 \\
\hline & & $-(12.44)$ & (3.90) & (2.47) & $-(1.87)$ & \\
\hline \multirow[b]{2}{*}{ Percentile } & & \multicolumn{4}{|c|}{ 2002-2000 (Normal / Dry) } & \\
\hline & Season & Intercept $\Delta$ & Min Temp & $\Delta$ Precip & $\Delta$ Precip Days & $\mathrm{N}$ \\
\hline \multirow{4}{*}{$10 \%$} & Summer & -0.28 & 0.12 & -0.09 & 0.04 & 3982 \\
\hline & & $-(4.54)$ & $(5.00)$ & $-(0.78)$ & $(1.20)$ & \\
\hline & Winter & -0.51 & -0.01 & -1.58 & 0.15 & 1992 \\
\hline & & $-(9.74)$ & $-(0.51)$ & $-(1.83)$ & (1.45) & \\
\hline \multirow{4}{*}{$25 \%$} & Summer & -0.43 & 0.18 & -0.14 & 0.08 & 3982 \\
\hline & & $-(6.28)$ & (6.86) & $-(1.15)$ & (2.34) & \\
\hline & Winter & -0.67 & -0.01 & -2.35 & 0.22 & 1992 \\
\hline & & -(12.37) & $-(0.69)$ & $-(2.53)$ & (2.01) & \\
\hline \multirow{4}{*}{$50 \%$} & Summer & -0.63 & 0.23 & -0.23 & 0.13 & 3982 \\
\hline & & $-(7.87)$ & (6.83) & $-(1.64)$ & (3.63) & \\
\hline & Winter & -0.90 & -0.01 & -1.99 & 0.11 & 1992 \\
\hline & & $-(14.41)$ & $-(0.27)$ & $-(1.34)$ & (0.59) & \\
\hline \multirow{4}{*}{$75 \%$} & Summer & -0.60 & 0.33 & -0.24 & 0.15 & 3982 \\
\hline & & $-(4.71)$ & (6.91) & $-(1.12)$ & (2.52) & \\
\hline & Winter & -1.15 & -0.03 & -3.73 & 0.31 & 1992 \\
\hline & & $-(12.80)$ & $-(0.79)$ & $-(2.06)$ & (1.45) & \\
\hline \multirow{4}{*}{$90 \%$} & Summer & -0.60 & 0.50 & -0.54 & 0.14 & 3982 \\
\hline & & $-(2.99)$ & (6.23) & $-(1.60)$ & (1.56) & \\
\hline & Winter & -1.53 & -0.05 & -3.48 & 0.19 & 1992 \\
\hline & & $-(8.53)$ & $-(0.64)$ & $-(1.02)$ & (0.46) & \\
\hline
\end{tabular}

${ }^{\mathrm{a}}$ The numbers in parenthesis are asymptotic Z-statistics. 
Table 4: Price Elasticity for Residential Water Demand ${ }^{\mathrm{a}}$

\begin{tabular}{crrrr}
\hline & \multicolumn{2}{c}{$2003-2000$ (Normal / Normal) } & \multicolumn{2}{c}{ 2002-2000 (Normal / Dry) } \\
\hline Percentile & \multicolumn{1}{c}{ Winter } & Summer & \multicolumn{1}{c}{ Winter } & Summer \\
\hline 10 & -1.93 & -0.99 & -1.63 & -0.35 \\
& $(-9.93)$ & $(-15.22)$ & $(-9.74)$ & $(-4.54)$ \\
25 & -1.72 & -0.85 & -1.34 & -0.32 \\
& $(-12.95)$ & $(-20.33)$ & $(-12.37)$ & $(-6.28)$ \\
50 & -1.54 & -0.68 & -1.17 & -0.3 \\
& $(-14.11)$ & $(-22.25)$ & $(-14.41)$ & $(-7.87)$ \\
75 & -1.6 & -0.56 & -1.01 & -0.19 \\
& $(-15.062)$ & $(-19.42)$ & $(-12.80)$ & $(-4.71)$ \\
90 & -1.53 & -0.45 & -0.94 & -0.13 \\
& $(-12.44)$ & $(-14.94)$ & $(-8.53)$ & $(-2.99)$ \\
\hline
\end{tabular}

${ }^{\mathrm{a}}$ The numbers in parentheses are asymptotic $\mathrm{Z}$ statistics, treating the price difference, price and quantity at their sample means as constants for estimating the variance of the estimated price elasticity. 